\title{
Serum 25-hydroxyvitamin D level during early pregnancy and type 1 diabetes risk in the offspring
}

\author{
M. E. Miettinen • L. Reinert • L. Kinnunen • \\ V. Harjutsalo • P. Koskela • H.-M. Surcel • \\ C. Lamberg-Allardt • J. Tuomilehto
}

Received: 4 November 2011 / Accepted: 21 December 2011 /Published online: 20 January 2012

(C) Springer-Verlag 2012

\begin{abstract}
Aims/hypothesis Vitamin D deficiency during the fetal period or infancy is one of the suggested environmental factors for type 1 diabetes and for its increasing incidence. To test
\end{abstract}

\author{
M. E. Miettinen · J. Tuomilehto \\ Department of Public Health, University of Helsinki, \\ Helsinki, Finland \\ M. E. Miettinen $(\bowtie) \cdot$ L. Reinert $\cdot$ L. Kinnunen $\cdot$ V. Harjutsalo $•$ \\ J. Tuomilehto \\ Diabetes Prevention Unit, \\ National Institute for Health and Welfare, \\ PO Box 30, 00271 Helsinki, Finland \\ e-mail: maija.miettinen@thl.fi \\ V. Harjutsalo \\ Folkhälsan Institute of Genetics, Folkhälsan Research Centre, \\ Biomedicum Helsinki, \\ Helsinki, Finland \\ V. Harjutsalo \\ Division of Nephrology, Department of Medicine, \\ Helsinki University Central Hospital, \\ Helsinki, Finland \\ P. Koskela $\cdot$ H.-M. Surcel \\ Child and Adolescent Health and Welfare Unit, \\ National Institute for Health and Welfare, \\ Oulu, Finland \\ C. Lamberg-Allardt \\ Calcium Research Unit, Department of Food and Environmental \\ Sciences, University of Helsinki, \\ Helsinki, Finland \\ J. Tuomilehto \\ South Ostrobothnia Central Hospital, \\ Seinäjoki, Finland
}

this hypothesis we compared serum 25-hydroxyvitamin D $(25(\mathrm{OH}) \mathrm{D})$ levels during early pregnancy in mothers of children who subsequently developed type 1 diabetes (case mothers) with mothers of non-diabetic healthy children (control mothers) of the same age.

Methods Children with type 1 diabetes were identified from the nationwide prescription register. $25(\mathrm{OH}) \mathrm{D}$ concentration was measured from serum samples collected during the first trimester of pregnancy from all Finnish women (Finnish Maternity Cohort). A total of 343 case mothers and 343 control mothers were included in the study. Samples were collected throughout the year. Samples from case and control mothers were matched on the day of collection.

Results Mean 25(OH)D levels in case mothers $(43.9 \mathrm{nmol} / \mathrm{l})$ and control mothers $(43.7 \mathrm{nmol} / \mathrm{l})$ were not different. Of all mothers, $481(70.1 \%)$ were vitamin $\mathrm{D}$-deficient or -insufficient.

Conclusions/interpretation No difference was found in serum $25(\mathrm{OH}) \mathrm{D}$ concentrations during first trimester of pregnancy between mothers whose children later on developed type 1 diabetes, and mothers of non-diabetic ' healthy' children of the same age. It is difficult to detect possible effects of mothers' vitamin D deficiency during early pregnancy on the development of type 1 diabetes in the offspring in this population, as such a large proportion of mothers were vitamin D-deficient or -insufficient.

Keywords 25-Hydroxyvitamin D · Pregnancy - Type 1 diabetes · Vitamin D

\author{
Abbreviations \\ 25(OH)D 25-Hydroxyvitamin D \\ FMC Finnish Maternity Cohort
}




\section{Introduction}

Vitamin D deficiency during the fetal period or infancy is one of the suggested environmental factors for type 1 diabetes and for its increasing incidence [1]. In Finland, located in the north and where type 1 diabetes incidence is the highest in the world [2], vitamin D deficiency has been shown to be common especially during the winter [3].

Vitamin D supplementation during infancy has been associated with decreased risk of type 1 diabetes in several studies [4-6], whereas in other studies no connection has been found between vitamin D supplementation [7] or intake [8] and type 1 diabetes. Some evidence has also been reported for an association between vitamin D supplementation during pregnancy and a decreased risk of type 1 diabetes [9], or reduced development of beta cell-specific autoantibodies [7] in the offspring. In other studies, however, no association was seen between maternal intake of vitamin $\mathrm{D}$ during pregnancy and risk of advanced beta cell autoimmunity [10] or type 1 diabetes [6] in the offspring. In these studies, vitamin D status was estimated from calculated supply from the diet and vitamin D supplements, without information on serum vitamin D levels. Serum 25hydroxyvitamin D $[25(\mathrm{OH}) \mathrm{D}]$ concentration reflects vitamin D obtained from the diet, supplements and sunlight, and is used as an indication of the vitamin D status of a person. Serum $25(\mathrm{OH}) \mathrm{D}$ concentration $<25 \mathrm{nmol} / 1$ is often considered as vitamin D deficiency [11], 25-50 nmol/1 as vitamin $\mathrm{D}$ insufficiency, $50-75 \mathrm{nmol} / \mathrm{l}$ as vitamin $\mathrm{D}$ sufficiency [12] and $>75 \mathrm{nmol} / \mathrm{l}$ as an optimal vitamin D level [13]. In a recent study by Simpson et al [8], 25(OH)D level of children at increased risk of developing type 1 diabetes was not associated with islet autoimmunity or progression of type 1 diabetes. Thus far no study has investigated association of serum $25(\mathrm{OH}) \mathrm{D}$ levels during pregnancy with risk of type 1 diabetes in the offspring.

The aim of this study was to compare serum $25(\mathrm{OH}) \mathrm{D}$ levels during the first trimester of pregnancy of mothers of children with type 1 diabetes (case mothers) with those of mothers of healthy children (control mothers) of the same age. We also studied the differences in proportions of case and control mothers with vitamin D deficiency, insufficiency, sufficiency and optimal levels of vitamin D.

\section{Methods}

Since 1983, serum samples have been collected from all pregnant women in Finland during the first trimester of pregnancy (the Finnish Maternity Cohort; FMC). The FMC stores serum samples (at $-20^{\circ} \mathrm{C}$ ) from each pregnancy from almost all $(98 \%)$ pregnant women in Finland. A sample of the serum is kept frozen for future use.
Initially, 751 case mothers were invited to participate in this study, of whom 498 (66.3\%) participated. Mothers were obtained from the Finnish Diabetes Register for children; this database has been described in detail elsewhere [14].

For each case mother, a corresponding control mother was selected according to the arrival of the serum samples in the FMC repository, with the case and control samples being collected on the same day. A control mother was invited to participate for each case mother, resulting in 343 casecontrol pairs. Where available, samples were collected from mothers during pregnancy of healthy siblings of the type 1 diabetes children, resulting in 137 samples from siblings. The mean duration of storage of the serum samples before the present vitamin D assay was 14.7 years (range 10 17 years).

The mean age at diagnosis of children with type 1 diabetes was 3.4 years (range 0-7 years). Informed consent was collected from all mothers, and the ethics committee of the Hospital District of Helsinki and Uusimaa approved the protocol.

Serum 25(OH)D was measured using an enzyme immunoassay method with IDS OCTEIA 25-Hydroxy vitamin D kit (Immunodiagnostic Systems, Boldon, UK). The intra- and inter-assay CVs were $3.57 \%$ and $3.68 \%$, respectively. The analytical reliability of the $25(\mathrm{OH}) \mathrm{D}$ assay was assured by participation in the vitamin D External Quality Assessment Scheme (DEQAS; Charing Cross Hospital, London UK).

25(OH)D concentrations were compared using Student's $t$ test. The differences in proportions of case and control mothers in the different vitamin $\mathrm{D}$ level groups were identified using Pearson's $\chi^{2}$ test; $p$ values $<0.05$ were considered statistically significant. Analyses were performed using PASW statistics 18 for Windows. As the time of sample collection was different in the siblings, season-standardised

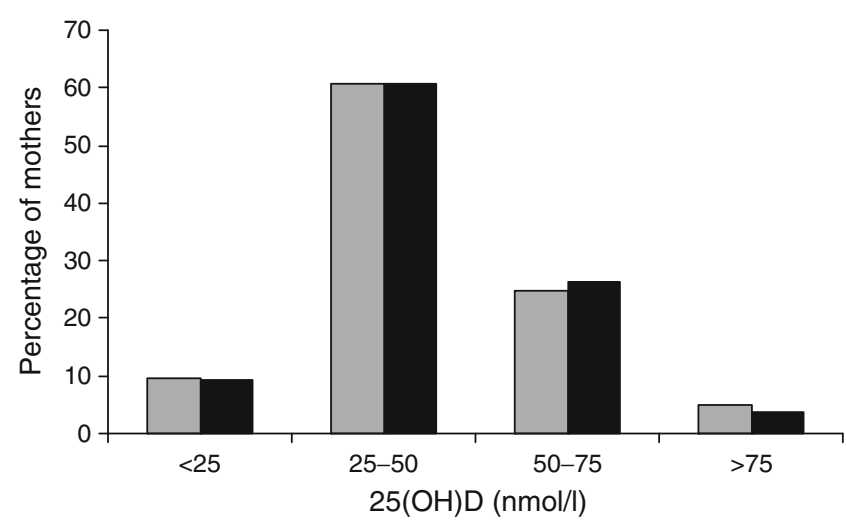

Fig. 1 Proportions of case (grey) and control mothers (black) with vitamin D deficiency ( $<25 \mathrm{nmol} / \mathrm{l} ; n=33$ and $n=32$ for case and control mothers, respectively), vitamin D insufficiency (25-49 nmol/1; $n=208$ and $n=208$ for case and control mothers, respectively), vitamin $\mathrm{D}$ sufficiency ( $50-75 \mathrm{nmol} / 1 ; n=85$ and $n=90$ for case and control mothers, respectively) and optimal ( $>75 \mathrm{nmol} / \mathrm{l} ; n=17$ and $n=13$ for case and control mothers, respectively) vitamin D status 
$25(\mathrm{OH}) \mathrm{D}$ values were calculated by multiplying the values with the correction factor.

\section{Results}

The mean 25(OH)D level of the case mothers during pregnancy was $43.9 \mathrm{nmol} / 1$ ( $n=343$; SD 16.9), and of the control mothers $43.5 \mathrm{nmol} / 1(n=343$; SD 16.6; $p=0.70)$.

For case mothers who had serum samples available from both the pregnancies of a type 1 diabetic child, and of a nondiabetic sibling $(n=137)$, the mean $25(\mathrm{OH}) \mathrm{D}$ level (using a correction factor i.e. season-standardised mean) during pregnancy of the type 1 diabetic child was $44.7 \mathrm{nmol} / \mathrm{l}$, and during pregnancy of the non-diabetic healthy child $44.1 \mathrm{nmol} / \mathrm{l}(p=0.60)$.

The proportions of mothers with vitamin D deficiency $(<25 \mathrm{nmol} / \mathrm{l})$, insufficiency ( $25-49 \mathrm{nmol} / \mathrm{l})$, sufficiency (50$75 \mathrm{nmol} / \mathrm{l})$ and optimal vitamin D status $(>75 \mathrm{nmol} / \mathrm{l})$ during pregnancy did not differ between the case and control mothers ( $p=0.88$; Fig. 1$)$.

Association of serum 25(OH)D level during pregnancy with the onset age of type 1 diabetes was analysed. There was no difference between children with onset of type 1 diabetes at the age of $0-3$ years $(44.0 \mathrm{nmol} / 1 ; n=177)$ and 4 7 years $(43.9 \mathrm{nmol} / 1 ; n=154 ; p=0.96)$.

\section{Discussion}

We evaluated whether vitamin D status during the first trimester of pregnancy was associated with the risk of type 1 diabetes in the offspring. We compared serum 25(OH)D levels during pregnancy in mothers of children who later developed type 1 diabetes (case mothers) with levels in mothers of healthy children (control mothers). No difference was seen between the mean 25(OH)D levels of the case and control mothers. Neither was there any difference in serum $25(\mathrm{OH}) \mathrm{D}$ levels during pregnancy in women with type 1 diabetic children and other pregnancies of healthy siblings.

The present study includes a unique sample set, which gave us an opportunity to analyse vitamin D status during pregnancy retrospectively, when it was already known which of the children later developed type 1 diabetes. As serum samples were collected nationwide from all pregnancies, both recruitment and participation bias are excluded. In contrast to most previous studies of the putative connection of vitamin $\mathrm{D}$ with type 1 diabetes [4-6, 8,9], we were able to measure the actual serum $25(\mathrm{OH}) \mathrm{D}$ level, which is a total result of all vitamin D supply from diet, sunlight and supplements.

Serum $25(\mathrm{OH}) \mathrm{D}$ concentration is known to vary according to season due to differences in the amount of sunlight. To avoid bias, we matched the sera of case and control mothers so that the samples were collected on the same day. However, there is a possibility that in spite of the chemical stability of 25 $(\mathrm{OH}) \mathrm{D}$, some degradation occurred during storage. But as the samples from the case and control mothers were collected on the same day and stored in the same freezer, any potential degradation of 25(OH)D should be approximately the same in the case and control samples. A considerable proportion of pregnant Finnish women in this study had serum 25(OH)D levels below optimal during the first trimester of pregnancy. To evaluate the possible degradation of $25(\mathrm{OH}) \mathrm{D}$ during storage, we compared samples that had been stored for 10 13 and $14-17$ years and found no difference in mean $25(\mathrm{OH})$ D concentrations. In another study using more recently collected FMC serum samples (less than 2 years before the analysis) [15], the mean $25(\mathrm{OH}) \mathrm{D}$ concentration was lower $(41.0 \mathrm{nmol} / \mathrm{l})$ than in the present study, where the samples had been stored and analysed by the same method in the same laboratory.

A limitation of the present study is that samples were collected only during the first trimester of pregnancy. In another study [15], the 25(OH)D levels of Finnish women were somewhat higher postpartum than during the first trimester of pregnancy, possibly indicating that an increased number of women use recommended vitamin D supplements during the last trimester than during the first trimester of pregnancy.

Our results indicate that it is unlikely that a relative vitamin D deficiency in pregnant women during early pregnancy contributes to the development of type 1 diabetes in the child. However, as a large proportion of the women studied had vitamin D deficiency or insufficiency, it is difficult to see the possible effect of vitamin D deficiency in the development of type 1 diabetes in the offspring. Thus, we cannot exclude the possibility that vitamin D deficiency acts as a risk-modifying factor only in those individuals who have a genetic susceptibility to type 1 diabetes. In addition, we cannot exclude the possibility that vitamin $\mathrm{D}$ deficiency may contribute to the high incidence of type 1 diabetes in Finnish children, although it may not be the main contributing factor.

Funding This study was supported by the Finnish Academy (grant 127219), the European Foundation for the Study of Diabetes, the EVO funding of the South Ostrobothnia Central Hospital from Ministry of Health and Social Affairs (EVO1107), the Biomedicum Helsinki Foundation, the Jalmari and Rauha Ahokas Foundation, the Yrjö Jahnsson Foundation, the Suoma Loimaranta-Airila Fund, the Onni and Hilja Tuovinen Foundation, and the Juho Vainio Foundation.

Duality of interest The authors declare that there is no duality of interest associated with this manuscript. The sponsors had no role in the design, data collection, data analysis, data interpretation, or writing or revisions of the report. The corresponding author had full access to all data in the study and had final responsibility to submit for publication.

Contribution statement All authors contributed to the conception and design of the study, analysis and interpretation of data, and drafting 
the article or revising it critically for important intellectual content. All authors gave final approval of the version to be published.

\section{References}

1. Hyppönen E (2010) Vitamin D and increasing incidence of type 1 diabetes - evidence for an association? Diabetes Obes Metab 12 (9):737-743

2. Harjutsalo V, Sjöberg L, Tuomilehto J (2008) Time trends in the incidence of type 1 diabetes in Finnish children: a cohort study. Lancet 371(9626): 1777-1782

3. Kauppi M, Impivaara O, Mäki J et al (2009) Vitamin D status and common risk factors for bone fragility as determinants of quantitative ultrasound variables in a nationally representative population sample. Bone 45(1):119-124

4. EURODIAB Substudy 2 Study Group (1999) Vitamin D supplement in early childhood and risk for type 1 (insulin-dependent) diabetes mellitus. Diabetologia 42:51-54

5. Hyppönen E, Läärä E, Reunanen A, Järvelin MR, Virtanen SM (2001) Intake of vitamin D and risk of type 1 diabetes: a birthcohort study. Lancet 358(9292):1500-1503

6. Stene LC, Joner G, Norwegian Childhood Diabetes Study Group (2003) Use of cod liver oil during the first year of life is associated with lower risk of childhood-onset type 1 diabetes: a large, populationbased, case-control study. Am J Clin Nutr 78(6):1128-1134

7. Brekke HK, Ludvigsson J (2007) Vitamin D supplementation and diabetes-related autoimmunity in the ABIS study. Pediatr Diabetes $8(1): 11-14$
8. Simpson M, Brady H, Yin X et al (2011) No association of vitamin $\mathrm{D}$ intake or 25-hydroxyvitamin D levels in childhood with risk of islet autoimmunity and type 1 diabetes: the Diabetes Autoimmunity Study in the Young (DAISY). Diabetologia 54(11):2779-2788

9. Stene LC, Ulriksen J, Magnus P, Joner G (2000) Use of cod-liver oil during pregnancy associated with lower risk of type 1 diabetes in the offspring. Diabetologia 43:1093-1098

10. Marjamäki L, Niinistö S, Kenward MG et al (2010) Maternal intake of vitamin D during pregnancy and risk of advanced beta cell autoimmunity and type 1 diabetes in offspring. Diabetologia 53(8):1599-1607

11. Nordic Council of Ministers (2004) Nordic nutrition recommendations 2004. Integrating nutrition and physical activity. Nordic Council of Ministers, Århus

12. Institute of Medicine, Food and Nutrition Board (2011) Dietary reference intakes for calcium and vitamin D. National Academy Press, Washington

13. Bischoff-Ferrari HA, Giovannucci E, Willett WC, Dietrich T, Dawson-Hughes B (2006) Estimation of optimal serum concentrations of 25-hydroxyvitamin D for multiple health outcomes. Am J Clin Nutr 84:18-28

14. Tuomilehto J, Lounamaa R, Tuomilehto-Wolf E et al (1992) Epidemiology of childhood diabetes mellitus in Finland-background of a nationwide study of type 1 (insulin-dependent) diabetes mellitus. The Childhood Diabetes in Finland (DiMe) Study Group. Diabetologia 35:70-76

15. Viljakainen HT, Saarnio E, Hytinantti T et al (2010) Maternal vitamin D status determines bone variables in the newborn. J Clin Endocrinol Metab 95(4):1749-1757 